\title{
Editorial: Rock Avalanches
}

\author{
O. Adrian Pfiffner ${ }^{1 *}$, Reginald L. Hermanns ${ }^{2}$, Tim R. Davies ${ }^{3}$ and John J. Clague ${ }^{4}$ \\ ${ }^{1}$ Institute of Geological Sciences, University of Bern, Bern, Switzerland, ${ }^{2}$ NORGES GEOLOG/SKE UNDERSØKELSE, Geohazard \\ and Earth Observations, Trondheim, Norway, ${ }^{3}$ School of Earth and Environment, University of Canterbury, Christchurch, \\ New Zealand, ${ }^{4}$ Department of Earth Sciences, Simon Fraser University, Burnaby, BC, Canada
}

Keywords: rock avalanches, dating rock avalanches, landscape evolution, fragmentation, run-out

Editorial on the Research Topic

Rock Avalanches

This Research Topic Rock Avalanches gathers high-quality original research articles, reviews and technical notes on the nature and mechanics of large rock avalanches with long run-out and associated secondary features such as lakes dammed by rock avalanche deposits.

Rock avalanches have volumes of millions of $\mathrm{m}^{3}$ or more, and large ones have major impacts on landscapes related to their source areas, travel paths and deposits. Key questions of rock avalanches include triggers and causes, mechanisms of long runout and the morphology of the rock avalanche deposits. Seismic shaking and extreme weather events are important triggering mechanisms, but some rock avalanches lack an obvious trigger. An important causative factor is the pre-existing structure of the displaced rock mass. The mechanisms of transport depend on the slope angle and shape of the sliding surface, the nature of the substrate on which the avalanche moves and the internal deformation that the rock avalanche is undergoing. The rock type and structure of the base of the rock avalanche is in many instances of paramount importance in the motion of the disintegrating rock mass. Several possibilities of how mobility and run-out are enhanced can be envisaged: 1) a mechanically weak layer within the rock mass from which the rock avalanche broke away, 2) strain softening by disintegration near the base and within the moving rock avalanche, 3) travel on ice or water-saturated unconsolidated sediment, and 4) energy transformation due to dynamic fragmentation. Analysis of the size and distribution of fragments within rock avalanche deposits, together with deposit morphology, provide insights into the internal deformation that accompanies the motion and final emplacement of the rock avalanche. All these factors contribute to the long run-out of rock avalanches, which augment the area of impact and hence landslide hazard.

This Research Topic adds to the state of knowledge of large rock avalanches and their impact on landscapes and society. It comprises contributions dealing with more generic questions of rock avalanches as well as case studies from very different places throughout the world.

\section{GENERIC PAPERS}

Received: 10 January 2021

Accepted: 14 January 2021

Published: 09 February 2021

Citation:

Pfiffner OA, Hermanns RL, Davies TR and Clague JJ (2021) Editorial: Rock Avalanches.

Front. Earth Sci. 9:651642. doi: 10.3389/feart.2021.651642

Knapp and Krautblatter present a theoretical analysis of energies involved in the movement of rock avalanches. Energy sources in the disintegration phase are potential (gravitational), elastic and kinetic energy. Energy sinks are friction, inelastic collision, entrainment, compressional deformation, chemical energy consumption, phase transitions, dust production, bouncing, sound, microseismicity and momentum of the solid-fluid transition. A better understanding of energy transformation and dissipation during disintegration, and of the residual kinetic energy of the rock avalanche, are keys to the mechanical and dynamic properties related to run-out. 
Secondary sediment mass flows in the so-called splash zone are often poorly preserved in the morphologic and stratigraphic record of rock avalanches but can be of considerable size when the rock avalanche impacts on valley fill sediments. Not including this secondary mass flow in the hazard zone can lead to a substantial underestimation of the total risk of a rock slope failure. Mitchel et al. present a probabilistic model of how to estimate the area affected by these secondary mass flows that is based on 32 well-documented rock avalanches, most of them since 2010 . Out of 13 post-2010 events nine produced a sediment mass flow.

An important task in landslide hazard assessment is estimating the volume likely to be released at each potential landslide site. For dealing with a large number of sites, Chih-Yu et al. propose an automated tool using volumeconstrained smooth minimal surfaces (differentiable surfaces that enclose a given landslide volume with the minimal surface area) to approximate the landslide failure surfaces. The method is tested on 24 known landslides and is able to generate acceptable failure surfaces. A set of assessment indices is employed to measure the fitness of the predictions, and the prediction fitness is compared with the landslide scarp geometry.

\section{CASE STUDIES}

Rock slope failures in most glaciated mountain chains yield almost exclusively young, mostly Holocene ages. In this study by McColl, a $50-100 \times 10^{6} \mathrm{~m}^{3}$ rock avalanche in the glaciated Rangitata Basin in Canterbury, New Zealand reveals a preHolocene age of $>16 \mathrm{ka}$ (and likely $>20 \mathrm{ka}$ ), making it the oldest reported alpine rock avalanche in New Zealand, and one of the oldest last-glaciation rock avalanches reported worldwide. The study confirms that while rock avalanches were occurring in the Southern Alps early in the last period of deglaciation, evidence for them persists only in the few environments that have conditions favourable for preservation.

Lagmay et al. report a devastating rock avalanche that occurred in 2018 in Naga City (Philippines). The rock avalanche initiated as translational slide in limestone lying on a weak base of sandstone and siltstone. As the failed rock mass gained momentum, its front accelerated and disintegrated into jigsaw-cracked blocks embedded in a non-graded matrix. Hummocks and large tilted toreva blocks are evidence of the acceleration and long run-out of the faster-moving front of the rock avalanche. The unexpectedly long run-out resulted in the loss of at least 78 lives.

Entrainment of substrate along the path of rock avalanches has often been observed. This back analysis by Chen et al. of the 2017 Xinmo rock avalanche using discrete element methods (3DEC) indicates that entrainment by plowing due to the impact of the rock avalanche outweighs the effect of basal abrasion. In addition, the model shows that the plowing causes first a deceleration of the movement until the entrained material contributes to the increase of the velocity by adding potential energy. A good fit of the run-out model with the observed magnification factor (2) indicates the suitability of such models for entrainment analysis.

Cihan et al. studied the Akdag rock avalanche, one of the largest known of such deposits in Turkey. The failure occurred along the contact zone of carbonates over flysch sediments and springs along this intersection suggest that water played a central role in conditioning the slope for failure. Using terrestrial cosmogenic nuclides, the authors show that the main event with a volume of $3{ }^{\star} 10^{8} \mathrm{~m}^{3}$ occurred $8.3 \pm 1.4 \mathrm{ka}$ years ago followed by a second event with much smaller volume $1.1 \pm 0.2 \mathrm{ka}$ ago.

Von Wartburg et al. studied a rock avalanche in northern Italy. The unusual morphology of the deposit with scarps, ridges and lineaments, was previously thought to indicate multiple events. The authors show that it was rather a single event, which occurred at $4.8 \pm 0.5 \mathrm{ka}$. By comparing with analog experiments, they conclude that the deposit morphology is the result of emplacement along the complex valley floor, including run-up and gravitational spreading of the moving mass.

The relation of rock avalanche deposits in the upper Ferret Valley with the 1717 historic Triolet rock avalanche in the Mont Blanc massif have long been in dispute as organic material related to the deposit resulted in varying ${ }^{14} \mathrm{C}$ ages. Encouraged by $19{ }^{10} \mathrm{Be}$ ages confirming that the deposits relate to that event Hajdas et al. sampled a stratigraphic succession of detritic and organic material in four pits within the disputed rock avalanche deposit. Out of 36 samples for AMS ${ }^{14} \mathrm{C}$ dating eight ages on wood fragments result in an age of $\sim 1,650-1950 \mathrm{AD}$. In the absence of any other historic events reported from this valley this confirms that the deposit indeed is related to the historically reported event in 1717 .

The Flims deposit, the largest in Europe, offers an opportunity to investigate the failure process as the source zone is well exposed and accessible. Well constrained engineering geology analyses of the pre-failure and triggering conditions allow inferences to be drawn about the release of the mass and the transition to a long-runout event. Low-strength marl-like layers suggest that failure could have been seismically or meteorologically triggered. The analyses by Aaron et al. also show that some mechanism to reduce strength immediately following failure is required to explain the mobility of the event.

Moreiras reviews the genesis of a previously studied chaotic deposit in the Blanco River basin (Argentina Andes) that has been interpreted as a either a debris flow or glacial deposit. The author conducted a detailed sedimentological and geomorphic study of the deposit and concludes that it was emplaced by a huge rock avalanche that traveled nearly $27 \mathrm{~km}$ and descended $4,700 \mathrm{~m}$ in altitude. Optically stimulated luminescence (OSL) ages on alluvial sediments associated with the landslide deposit suggest an age of $\sim 35-39 \mathrm{ka}$ for the event. The rock avalanche may have been triggered by an earthquake, given the presence of a nearby active fault system and a cluster of seven Late Pleistocene rock avalanches in the region. 
Pacheco et al. studied the distal portion of the oldest rock avalanche deposit in Yosemite Valley, which they dated to about $16.1 \mathrm{ka}$ using the cosmogenic ${ }^{10} \mathrm{Be}$. They identified the interface between the rock avalanche deposit and underlying late Pleistocene glaciofluvial sediments using ground penetrating radar (GPR) and electrical resistivity tomography (ERT) methods. Their findings provide an improved understanding of the sedimentation history in Yosemite Valley, inform hazard and risk assessment in the national park, and show the value of geophysical methods for three-dimensional investigation of buried landslide deposits.

Bessette-Kirton and Coe created an inventory of rock avalanches in a $3,700 \mathrm{~km}^{2}$ area of the Saint Elias Mountains (Alaska) to differentiate between the frequency of landslides related to the geologic and active tectonic setting of the region, and landslides triggered by climate change. They found a temporal cluster of 41 rock avalanches that happened between 2013 and 2016 and correlated with above-average air temperatures. Most of these rock avalanches initiated from bedrock ridges in probable permafrost zones, suggesting that permafrost degradation could be an important factor contributing to rock-slope instability in the region.

\section{AUTHOR CONTRIBUTIONS}

All authors listed have made a substantial, direct and intellectual contribution to the work, and approved it for publication.

\section{ACKNOWLEDGMENTS}

We thank all authors for their valuable contribution to this Research Topic, the reviewers who shared their precious time to improve the manuscripts, the members of the Frontiers Team and the Editor in chief for their help at different stages of preparing this collection of papers.

Conflict of Interest: The authors declare that the research was conducted in the absence of any commercial or financial relationships that could be construed as a potential conflict of interest.

Copyright (c) 2021 Pfiffner, Hermanns, Davies and Clague. This is an open-access article distributed under the terms of the Creative Commons Attribution License (CC $B Y)$. The use, distribution or reproduction in other forums is permitted, provided the original author(s) and the copyright owner(s) are credited and that the original publication in this journal is cited, in accordance with accepted academic practice. No use, distribution or reproduction is permitted which does not comply with these terms. 